\title{
O IMPACTO TRIBUTÁRIO NA DETERMINAÇÃO DO PREÇO DE TRANSFERÊNCIA NA IMPORTAÇÃO: ESTUDO DE CASO
}

\section{THE IMPACT OF TAX IN THE DETERMINATION OF TRANSFER PRICING IN THE IMPORT CASE STUDY}

\author{
Silvia Consoni ${ }^{1}$; Sergio Murilo Petri ${ }^{2}$; Alexandre Zoldan da Veiga ${ }^{3}$ \\ ${ }^{1}$ Universidade Federal de Santa Catarina - UFSC - Florianópolis - Brasil \\ silviaconsoni@yahoo.com.br \\ ${ }^{2}$ Universidade Federal de Santa Catarina - UFSC - Florianópolis - Brasil \\ smpetri@gmail.com \\ ${ }^{3}$ Universidade Federal de Santa Catarina - UFSC - Florianópolis - Brasil \\ azveiga@floripa.com.br
}

\begin{abstract}
Resumo
As empresas tendem nos negócios internacionais intrafirma a direcionar os lucros de forma mais conveniente utilizando-se, dentre outros mecanismos, da política de preços de transferência. Os desdobramentos tributários decorrentes dessas operações levaram diversos países, dentre eles o Brasil, a temerem pela perda das receitas fiscais. A legislação brasileira sobre preços de transferência, por meio de metodologia específica, determina o cálculo dos custos máximos dedutíveis na importação e o reconhecimento da receita mínima nas exportações de bens, direitos $e$ serviços. $O$ objetivo deste estudo consiste em identificar os reflexos tributários decorrentes da utilização do método de cálculo denominado Preço de Revenda menos o Lucro (PRL 60\%). Esta pesquisa de caráter descritivo está dividida em dois momentos: pesquisa bibliográfica e estudo de caso realizado em uma empresa de eletroeletrônicos. Os resultados obtidos permitem inferir que o cálculo do preço parâmetro, se limitado a metodologia PRL 60\%, pode interferir significativamente no resultado da empresa e contribuir para o mero arbitramento do que seria o preço justo. Consequentemente, sua utilização ocasiona aumento da base de cálculo dos tributos incidentes sobre a renda.
\end{abstract}

Palavras-chave: preço de transferência; importação; planejamento tributário.

\section{Introdução}

A internacionalização das operações comerciais, gradualmente, levou as empresas a reformularem suas estratégias de negócio para que, diante de relações mais competitivas, pudessem intensificar o comércio de produtos e serviços, propiciar melhor alocação da estrutura produtiva e administrativa e, até mesmo, atuar em diferentes ramos de negócio.

Em um sistema de produção internacional não são apenas as questões relacionadas à gestão de custos e aos aspectos logísticos e mercadológicos que influenciam nos resultados esperados. É 
necessário, ainda, considerar as implicações tributárias, dentre elas, o controle fiscal do preço de transferência.

O preço de transferência reflete aspectos de fundo econômico e organizacional. De acordo com Horngren, Sundem e Stratton (2004, p. 340), preços de transferência "são os montantes cobrados por um segmento de uma organização pelos produtos ou serviços que fornece a outros segmentos da mesma organização". Este pode ser utilizado em transações internas entre divisões da mesma empresa ou no comércio internacional intrafirma.

Nas operações entre divisões, o preço de transferência afeta as receitas da unidade que está transferindo e os custos da que está recebendo e, consequentemente, interfere na avaliação do desempenho gerencial e na lucratividade de ambas (HANSEN; MOWEN, 1993, p. 330). Sob essas condições, a política de preços pode ser centralizada e, assim, diferir significativamente dos preços de mercado.

No comércio internacional entre partes relacionadas existem as mesmas implicações, todavia, os desdobramentos tributários decorrentes dessas operações levaram diversos países, dentre eles o Brasil, a temerem pela perda das receitas fiscais. Em decorrência dessa preocupação, resultaram políticas internacionais sobre preços de transferência como forma de coibir a fixação de preços artificiais.

No Brasil os critérios para determinação e controle fiscal do preço de transferência no comércio exterior estão previstos na Lei $n^{\circ}$ 9.430/96, atualmente regulamentada pela Instrução Normativa (IN) - SRF no $243 / 2002$.

Essa legislação, por meio de metodologia específica, determina o cálculo dos custos máximos na importação e da receita mínima nas exportações de bens, direitos e serviços. Na importação, se constatado que o preço praticado é superior ao de mercado resultará em ajustes que aumentam a base de cálculo do imposto de renda pessoa jurídica (IRPJ) e da contribuição social sobre o lucro líquido (CSLL) e, inclusive, pode ocasionar dupla incidência, no caso, bitributação. Portanto, pergunta-se: qual é o impacto tributário na determinação do preço de transferência na importação de bens entre partes vinculadas no Brasil?

O objetivo deste artigo é, a partir do estudo de caso realizado em uma empresa de eletroeletrônicos, identificar os reflexos tributários decorrentes da utilização do método de cálculo denominado Preço de Revenda menos o Lucro (PRL 60\%).

A relevância deste estudo reside em fornecer subsídios para a elaboração de uma política de preço de transferência sob a perspectiva do planejamento tributário. O estudo de caso limita-se a considerar apenas um dos métodos estabelecidos na legislação brasileira específica sobre esse tema e a utilizar informações repassadas pela empresa na qual se realizou a pesquisa.

Este artigo está organizado em seis seções, incluindo esta de caráter introdutório. Na seção 
2, apresenta-se a revisão da literatura sobre o tema proposto e, posteriormente, na seção 3 descrevese a metodologia utilizada. A seção 4 compreende a apresentação e discussão dos resultados obtidos e a seção 5 traz as reflexões sobre o alcance do objetivo proposto e sugestões para trabalhos futuros. Por fim, incluem-se as referências de publicações que embasaram esta pesquisa.

\section{Fundamentação teórica}

Para viabilizar a consecução do objetivo proposto são abordados nesta seção conceitos e características relacionadas ao controle fiscal do preço de transferência e ao planejamento tributário.

\subsection{Controladoria e planejamento tributário}

As empresas, com o objetivo de reduzir a carga tributária e obter vantagens competitivas, tendem nos negócios internacionais intragrupo a direcionar os lucros de forma mais conveniente. Para tanto, utilizam, dentre outros mecanismos, da política de preços de transferência. No entanto, não é recomendável estabelecer um preço de transferência que maximize o lucro global da organização sem dar a devida atenção para a variável fiscal.

Sob a ótica da justa repartição das receitas tributárias tal tema reflete os limites entre a evasão e a elisão. Uma das conclusões da pesquisa conduzida globalmente por Ernst \& Young (2011) é que as autoridades fiscais, por meio de iniciativas multilaterais e legislação específica, estão cada vez mais inclinadas a coibirem a manipulação dos preços. De acordo com o estudo intitulado "2010 Global transfer pricing survey", das 877 multinacionais pesquisadas em 25 países, $68 \%$ dos respondentes foram fiscalizados em 2010. Ainda, essa pesquisa aponta que as empresas estão cada vez mais conscientes da necessidade de considerar as implicações fiscais no planejamento e na implementação de projetos de reestruturação empresarial (ERNST; YOUNG, 2011).

Nessas circunstâncias, a adoção de um planejamento tributário torna-se indispensável na manutenção das atividades econômicas e na conquista de novos mercados. Segundo Oliveira et al. (2007, p. 38) o planejamento tributário é um “estudo prévio à concretização dos fatos administrativos, dos efeitos jurídicos, fiscais e econômicos de determinada decisão gerencial, com o objetivo de encontrar a alternativa legal menos onerosa para o contribuinte". Portanto, para que funcione como uma ferramenta de correlação entre fatores de competitividade e de estratégia de negócios deve atender aos requisitos legais, ou seja, as possibilidades permitidas em lei ou aquelas em que a lei não impõe restrições.

Para a realização de uma política de gestão tributária as empresas precisam reconhecer que garantir o recolhimento dos tributos é apenas um dos compromissos inerentes à atividade desenvolvida. O diferencial está em identificar todos os tributos incidentes no ciclo operacional, 
analisá-los individualmente e no conjunto, de forma a evitar, sempre que possível, o desembolso indevido (ESNOLDE et al., 2009). Assim, qualquer transação econômica só deve ser realizada se for considerado adequado seu custo tributário. Isto implica em proceder não só a análise econômica e financeira, mas do fundamento jurídico, do cumprimento das obrigações acessórias e da prática contábil.

Para tanto, a controladoria é apontada como o órgão administrativo capaz de conduzir todo o processo de gestão tributária, pois detém os recursos para inseri-lo em todas as fases do ciclo produtivo e comercial, ou seja, em uma visão sistêmica de estratégia de negócios da organização.

Segundo Nascimento e Reginato (2007, p. 237), a competência da controladoria na gestão tributária, reside em:

\footnotetext{
- monitorar e expor para os gestores as principais informações contidas nas declarações de impostos, inclusive ressaltar algum possível efeito que esta possa gerar para a empresa; - supervisionar todas as questões relacionadas à apuração de tributos, incluindo a condução de um programa eficaz de gerenciamento de tributos que envolve todos os segmentos da corporação e forneça regras e procedimentos padronizados para atender as leis, normas e regulamentos pertinentes.

- coordenar a integração entre as dimensões de controle de custos, controle de estoques, controle de ativos e controle contábil, na qual estão inseridos os tributos (NASCIMENTO; REGINATO, 2007, p.237).
}

A singularidade desse conjunto de competências está em considerar as oportunidades e restrições de cada ramo de negócio como, por exemplo, o aproveitamento de incentivos fiscais. Neste caso, o uso do regime aduaneiro drawback possibilita a redução considerável dos tributos incidentes na importação e na exportação, além de proporcionar benefícios no fluxo de caixa. (SAGAZ; SAGAZ, 2007).

Sob essa perspectiva, a controladoria não pode limitar-se à análise e controle das informações financeiras sem considerar a participação dos tributos nessa questão. Sagaz (2009), ao analisar esse aspecto, constata que a atuação da controladoria junto ao departamento de compras é relevante para garantir a redução dos custos de produção, pois o conhecimento dos compradores sobre tributos às vezes é bastante limitado.

Nesse ínterim, o profissional da controladoria no desempenho de suas funções necessita apresentar, dentro outros, sólido conhecimento contábil e das implicações fiscais que afetam o resultado da empresa, bem como disposição para manter-se atualizado devido à complexidade da legislação fiscal e suas constantes mudanças. Contudo, tais aspectos ainda são negligenciados por estes profissionais, o que leva Esnolde et al. $(2009$, p.12) a inferir que "os controllers não possuem percepção para o desenvolvimento de uma gestão tributária eficiente". Certamente, este fato prejudica as empresas quanto aos diferenciais de competitividade na prática de preços e na gestão de custos, uma vez que a carga tributária pode, até mesmo, inviabilizar determinados negócios. 


\title{
2.2 Legislação brasileira sobre preços de transferência
}

As regras de preços de transferência no território nacional entraram em vigor em $1^{\circ} \mathrm{de}$ janeiro de 1997, após a publicação da Lei no 9.430, de 27 de dezembro de 1996. A partir desse momento, o Brasil passou a integrar o pequeno conjunto de países que possuíam legislação para verificação dos preços de transferência no comércio exterior.

O termo preço de transferência, numa acepção estritamente fiscal brasileira:

\begin{abstract}
tem sido utilizado para identificar os controles a que estão sujeitas as operações comerciais ou financeiras realizadas entre partes relacionadas, sediadas em diferentes jurisdições tributárias, ou quando uma das partes está sediada em paraíso fiscal. Em razão das circunstâncias peculiares existentes nas operações realizadas entre essas pessoas, o preço praticado nessas operações pode ser artificialmente estipulado e, conseqüentemente, divergir do preço de mercado negociado por empresas independentes, em condições análogas - preço com base no princípio arm's length (SECRETARIA DA RECEITA FEDERAL, 2005, questão 672).
\end{abstract}

Nota-se que esse entendimento pressupõe a existência de divergência entre o preço efetivamente utilizado e o preço que seria fixado caso a negociação envolvesse empresas independentes. Contudo, para Silva (2007, p. 334), as empresas podem encontrar dificuldades para apurar o preço de mercado se adotada particular estratégia nos negócios. Assim, o termo preço de transferência deve ser utilizado com cautela, pois não pode ser confundido simplesmente com problemas de fraudes tributárias ou evasão fiscal.

Internacionalmente, as diretrizes sobre o assunto são divulgadas pela Organização para a Cooperação e Desenvolvimento Econômico (OECD). Apesar de algumas diretrizes da OECD estarem presentes na legislação brasileira sobre preços de transferência, o Brasil ainda não é paísmembro.

Essa organização considera que o termo preço de transferência deve ser neutro e pautar-se no princípio do valor de mercado (arm’s length principle). Sob tal princípio, o vínculo societário existente entre as empresas não afetaria as condições comerciais pactuadas. Nesse sentido, caberia às empresas reunir evidências que satisfaçam o valor de mercado, sem que fosse necessário utilizar apenas os métodos estabelecidos em normas específicas, como ocorre no Brasil (LIMA NETO, 2007, p. 35-36). Esta é, inclusive, uma das principais críticas a legislação brasileira sobre o tema, pois se entende que a mesma estabeleceu critérios rígidos para a formação do preço de transferência implicando, inclusive, na adoção de margens fixas de lucro.

Recentemente, na tentativa de eliminar a litigiosidade na aplicação de alguns dispositivos, principalmente em relação à adequação da $\mathrm{IN}-\mathrm{SRF} \mathrm{n}^{\circ}$ 243/02, foi editada a Medida Provisória $\mathrm{n}^{\circ}$ 478/09. Todavia, a mesma perdeu sua eficácia em junho de 2010, por não ter sito convertida em lei em tempo hábil.

Atualmente, as operações comerciais sujeitas ao controle fiscal do preço de transferência 
estão previstas na Lei $n^{\circ}$ 9.430/96, art. $18, \S 9^{\circ}$ e compreendem tanto a importação quanto a exportação de bens, serviços e direitos, pagamento ou crédito de juros decorrentes de operações financeiras cujos contratos não estejam registrados no Banco Central do Brasil - BACEN, bem como juros auferidos nessas operações. Excluem-se desse controle o pagamento de royalties e assistência técnica, administrativa ou assemelhados. Ainda assim, é necessário que quaisquer dessas operações sejam realizadas por pessoas físicas ou jurídicas vinculadas, uma residente ou domiciliada no Brasil e a outra no exterior. Se não forem vinculadas, deve-se observar se a transação comercial está sendo realizada com pessoa física ou jurídica residente ou domiciliada em países com tributação favorecida e considerados paraísos fiscais.

\subsubsection{Pessoa vinculada}

A legislação brasileira sobre preço de transferência adotou uma concepção bastante abrangente de pessoa vinculada, de tal forma, que para caracterizá-la não basta existir o controle societário e administrativo de uma das partes.

As hipóteses ou circunstâncias que justificam a existência de interdependência nas operações de importação ou exportação estão elencadas no art. 23, incisos I a X, da Lei $n^{\circ}$ 9.430/96. Segundo esse dispositivo, a pessoa vinculada é aquela residente ou domiciliada no exterior sob a forma de matriz, filial ou sucursal da pessoa jurídica domiciliada no Brasil, bem como, a controladora, controlada ou coligada nos limites estabelecidos na Lei $\mathrm{n}^{\circ}$ 6.404/76 - Lei das Sociedades Anônimas. Além disso, entende-se por pessoa vinculada aquela que, para a execução de qualquer empreendimento, constituir associações (consórcio ou condomínio); obtiver exclusividade com agentes, distribuidores ou concessionários e for parente, até terceiro grau, cônjuge ou companheiro de diretores da empresa e de sócio-acionista controlador de forma direta ou indireta.

Para Pricewaterhousecoopers (2000, p. 17), as críticas ao vínculo comercial residem na

\footnotetext{
hipótese de vinculação entre empresas que não mantêm qualquer laço societário ou administrativo[...] como aquela em que um incorporador de imóvel comercial vende terreno a diversas empresas, que nele pretendem construir centro comercial, no qual terão suas sedes e escritórios administrativos. A aplicação da regra estará vinculando-as, criando o ônus de submissão a um controle de preços sem qualquer base econômica que autorize a presunção de prática de preços entre elas, que não decorrente das regras livres de mercado (PRICEWATERHOUSECOOPERS, 2000, p.17).
}

A IN - SRF no 243/02 atrelou ao conceito de pessoa vincula o de interposta pessoa. Esta instrução considera no art. $2^{\circ}, \S 5^{\circ}$ que as normas sobre preço de transferência aplicam-se "às operações efetuadas pela pessoa jurídica domiciliada no Brasil, por meio de interposta pessoa não caracterizada como vinculada, que opere com outra, no exterior, caracterizada como vinculada à empresa brasileira" como, por exemplo, nas operações intermediadas por trading company. Certamente, esta medida tem o propósito de dificultar a arbitrariedade das empresas na produção de 
provas que demonstrem a inexistência de vínculo no comércio exterior.

Para Françoso (2007, p. 49-50) trata-se de uma controvérsia, pois essa situação não foi prevista na Lei $n^{\circ}$ 9.430/96 e, por seguinte, cabe ao ato normativo apenas limitar-se a estabelecer a aplicação de um ato legal, sem inovar. Contudo, para a Secretaria da Receita Federal essa situação é legítima e decorre da intermediação comercial realizada por importadoras e exportadoras independentes, quando o fim específico é o comércio entre pessoas vinculadas. Nessa hipótese, tais empresas estão sujeitas às regras de preços de transferência, quer esteja ou não domiciliada no Brasil (SECRETARIA DA RECEITA FEDERAL, 2005, questões 679 e 680).

Complementarmente, como apresenta Lima Neto (2007, p. 58), a Lei ${ }^{\circ}$ 11.281/06 prevê, especificamente no art. 14, que nos casos onde o importador adquire mercadorias no exterior para revenda a encomendante pré-determinado, tanto o importador como o encomendante devem proceder ao controle fiscal dos preços de transferência, mesmo não configurando importação por conta e ordem de terceiros, como ocorre naquelas realizadas por interposta pessoa.

$\mathrm{Na}$ importação por encomenda existem "duas transações: uma entre o exportador, no exterior, e o importador, no País e outra, ajustada previamente, entre o último e o encomendante" (LIMA NETO, 2007, p. 59). Assim, a importação realizada sob encomenda difere da realizada por interposta pessoa apenas quando o bem importado é repassado a terceiro com valor superior ao da aquisição e, por isso, entende-se que deve submeter-se ao controle fiscal do preço de transferência.

\subsubsection{Metodologias de cálculo do preço parâmetro na importação}

Para comprovar a adequação dos preços na importação de insumos, objeto deste estudo, a empresa pode optar por um dos três métodos de cálculo inscritos na Lei ${ }^{\circ}$ 9.430/96. Tais métodos serão apresentados adiante e compreendem: a) Preços Independentes Comparados - PIC; b) Preço de Revenda menos o Lucro - PRL 60\% e; c) Custo do Produto menos o Lucro - CPL $20 \%$.

Internacionalmente, as diretrizes de cálculo com base nos métodos PIC e CPL são os mais utilizados pelas empresas. Ernst \& Young (2011) apontam que 30\% das empresas pesquisadas utilizam o método PIC e $27 \%$ utilizam o CPL para demonstrar o preço parâmetro de bens e insumos.

O contribuinte, por meio desses métodos, obtém o preço parâmetro que será utilizado na comparação com o preço efetivamente praticado. Para tanto, o valor do frete e do seguro, bem como dos tributos incidentes na importação, se suportados pelo importador, integram o custo para efeito de dedutibilidade e formação da base de cálculo dos tributos incidentes sobre a renda.

Os juros das vendas a prazo deverão ser excluídos com base na taxa praticada pela empresa, quando comprovada sua aplicação em todas as vendas a prazo durante todo o prazo concedido para pagamento. Caso isso não seja possível deve-se, conforme IN - SRF 243/02, art. 12 , $\S \S 5^{\circ}$ e $6^{\circ}$, ter 
como base para as vendas realizadas no mercado interno a taxa referencial do Sistema Especial de Liquidação e Custódia (SELIC) e para as vendas no mercado externo deve-se utilizar a taxa Libor.

Quando utilizado mais de um método, será considerado custo dedutível o maior valor apurado. No entanto, a opção por um dos métodos de cálculo deverá ser consistente durante todo o período fiscal e aplicado individualmente para cada bem importado. Portanto, não é permitida a compensação de margens entre os diferentes bens, serviços e direitos. Se o preço de compra for maior que o preço parâmetro apurado deve-se tributar a diferença, caso seja menor ou igual deve-se considerar o valor constante nos documentos de importação.

A Secretaria da Receita Federal, conforme IN - SRF no 243/02, art. 38, admite ser satisfatória a margem de divergência de até 5\%, para mais ou para menos, do preço apurado por qualquer um dos métodos em relação àquele constante nos documentos de importação. Até o limite de 5\% de divergência nenhum ajuste será exigido.

Essa instrução normativa também indica, nos art. 32 e 33, que o contribuinte ou entidade de classe pode pleitear junto ao Ministro da Fazenda redução das margens de lucro estabelecidas para o cálculo do preço parâmetro com base nos métodos PRL e CPL. Para tanto, a solicitação deverá conter a indicação do prazo para vigência das margens sugeridas e os demonstrativos dos custos de produção, do total anual das compras e vendas do objeto da solicitação, dos fretes e seguros, seguidos de cópia dos documentos originais que justifiquem as mesmas. Adverte-se, no entanto, que a Lei $n^{\circ} 9.430 / 96$ não contempla esses aspectos.

\section{- Método dos Preços Independentes Comparados - PIC}

Este método é definido na Lei $\mathrm{n}^{\circ}$ 9.430/96, art. 18, inciso I como a média aritmética dos preços de bens, serviços ou direitos, idênticos ou similares, apurados no mercado brasileiro ou de outros países, em operações de compra e venda em condições de pagamento semelhantes.

Considera-se similar, conforme IN - SRF $n^{\circ} 243 / 02$, art. 28, o que em uso na finalidade a que se destina apresentar simultaneamente, mesma natureza e mesma função, ser passível de substituição mútua e ter especificações equivalentes.

Para fins de ajuste na apuração do IRPJ e da CSLL é necessário comparar os preços dos bens, serviços ou direitos fornecidos por uma empresa vinculada com aqueles: a) vendidos pela mesma empresa exportadora a pessoas jurídicas não vinculadas; b) adquiridos pelo importador de pessoas jurídicas não vinculadas e; c) comercializados entre pessoas jurídicas não vinculadas.

A empresa pode optar pelo preço derivado da utilização de apenas um dos critérios acima ou da combinação de ambos. O preço obtido será, então, ajustado considerando as diferenças nas condições de negócio, de natureza física e de conteúdo. Portanto, observar os aspectos relacionados às operações atípicas, previstas IN - SRF no 243/02, art. 31, é de extrema utilidade para evitar 
ajustes fiscais, uma vez que, as vendas ocorridas em eventos sazonais, como na liquidação de estoque, não devem ser consideradas no cálculo do preço parâmetro.

Acrescenta-se que o contribuinte deve ficar atento aos acordos de preços, pois em determinados setores da economia esta pode ser uma prática corriqueira entre empresas independentes em algumas situações como, por exemplo, para garantir o fornecimento de um produto com volume de produção limitado.

Os documentos de suporte para a utilização desse método correspondem, basicamente, as commercial invoices e/ou notas fiscais referentes às operações tomadas para comparação de empresas não vinculadas. No entanto, a legislação não determina um número específico de operações que serão submetidas à avaliação.

\section{- Método do Preço de Revenda menos Lucro - PRL}

Para efeito do método PRL, o art. 18, inciso II, da Lei $\mathrm{n}^{\circ}$ 9.430/96 estabelece que os custos máximos admitidos na importação de bens, serviços e direitos entre pessoas vinculadas é a média aritmética das receitas obtidas na venda do que foi importado, diminuídas: a) dos descontos incondicionais concedidos; b) dos impostos e contribuições incidentes sobre as vendas e integrantes do preço; c) das comissões e corretagens creditadas e dos juros inseridos nas vendas a prazo e; d) da margem de lucro de 20\% (vinte por cento), na hipótese de revenda sem que haja, no País, agregação de valor ao custo, ou da margem de lucro de $60 \%$ (sessenta por cento), na hipótese de aplicação na produção.

A margem de lucro de $60 \%$ foi acrescentada posteriormente ao texto da Lei $\mathrm{n}^{\circ}$ 9.430/96, quando de sua alteração pela Lei $n^{\circ}$ 9.959/00 regulamentada pela IN - SRF n ${ }^{\circ} 32 / 01$, que em 2002 foi revogada pela IN - SRF n ${ }^{\circ} 243 / 02$, em vigor.

Esta última instrução apresentou entendimento divergente em relação ao exposto na Lei $\mathrm{n}^{\circ}$ 9.959/00 quanto ao emprego da margem de lucro 60\%. Para Borges (2007), a margem de lucro que deveria ser aplicada apenas sobre o preço líquido de venda do produto acabado diminuído do valor agregado no País teve outro tratamento. Em decorrência disso, a margem de lucro passou a ser calculada sobre a parcela do preço líquido de venda do produto acabado. Essa interpretação resulta em maior ajuste fiscal e, consequentemente, aumenta a base de cálculo do IRPJ e da CSLL, o que torna a legalidade desse dispositivo questionável (BORGES, 2007, p. 69).

Apesar dessa controvérsia, o método PRL apresenta a vantagem de sua utilização independer de informações repassadas por terceiros. Além disso, ressalta-se que o PRL 60\% é o único método viável para o cálculo do preço parâmetro quando o insumo importado não possuir similar no mercado, como produtos semi-elaborados, ou quando o produtor localizado no exterior não tem interesse em demonstrar o custo de produção. Essa limitação existe porque os demais 
métodos fazem referência de sua aplicabilidade aos bens, serviços e direitos idênticos ou similares.

- Método do Custo de Produção mais Lucro - CPL

Esta metodologia é utilizada, segundo a Lei n 9.430/96, art. 18, inciso II, para representar o custo médio de produção dos bens, serviços ou direitos, idênticos ou similares, no país onde tiverem sido originalmente produzidos, acrescidos de impostos e taxas cobrados no referido país na exportação e de margem de lucro de $20 \%$ calculada sobre o custo apurado.

Para viabilizar a utilização do CPL os custos de produção (custos de aquisição de matériasprimas e produtos intermediários, custo de mão de obra, quebras e perdas) deverão ser demonstrados discriminadamente por componente e respectivo fornecedor. Essas informações poderão ser obtidas da empresa fornecedora ou de outras empresas localizadas no país de origem do bem, serviço ou direito.

Observa-se que as variáveis utilizadas para a apuração do preço parâmetro através do método CPL dependem, exclusivamente, de informações de terceiros. Isto pode inviabilizar de certa forma sua aplicabilidade em determinadas circunstâncias, principalmente, porque os custos de produção são informações confidenciais e de estratégia dos negócios.

A documentação comprobatória do preço parâmetro, por ter procedência estrangeira, deverá ser notarizada, consularizada, traduzida e juramentada para ter validade perante as autoridades brasileiras. Acrescenta-se, ainda, que em caso de utilização de produto similar para aferição do preço, o custo de produção deverá ser ajustado em função das diferenças existentes.

\subsection{Tributação da renda no Brasil}

O preço de transferência, se considerado mecanismo para o direcionamento de lucros no comércio exterior, tem implicações tanto na determinação da base de cálculo do imposto sobre a importação (Acordo de Valoração Aduaneira - Decreto $n^{\circ}$ 2.498/98) como na tributação da renda

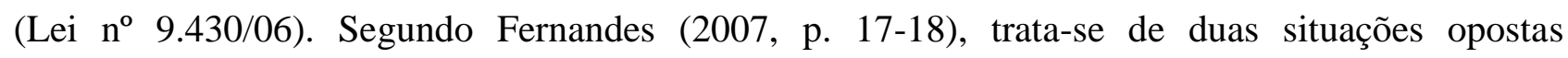
"enquanto a fiscalização do valor aduaneiro visa aumentar a base de cálculo da TEC [Tarifa Externa Comum], a auditoria fiscal no caso da renda tende a reduzir o preço da importação, o que reduz o custo e, em decorrência, aumenta o resultado tributável”.

Este último aspecto, por ligar-se ao objetivo deste estudo, convém ser analisado na sequência, uma vez que o custo de importação e os ajustes decorrentes do preço de transferência são itens considerados na apuração do IRPJ e da CSLL. Essa questão é relevante apenas para as pessoas jurídicas enquadradas na tributação sobre o lucro real, devido ao limite para a dedutibilidade dos custos e despesas.

A inter-relação entre preços de transferência e a tributação da renda no Brasil reside na 
adoção, desde a vigência da Lei no 9.249/95 em $1^{\text {o }}$ de janeiro de 1996, do critério da renda mundial para a tributação das pessoas jurídicas. Conforme prevê o art. 25 dessa Lei, são tributados no País os lucros, rendimentos e ganhos de capital auferidos no exterior por contribuintes residentes ou domiciliados no Brasil.

Até 1995 a tributação sobre a renda ocorria com base em dois princípios: o da universalidade, aplicado as pessoas físicas e, o da territorialidade aplicado as pessoas jurídicas. Como tais princípios delimitam a ocorrência do fato gerador, somente sob o princípio da universalidade é passível de tributação a renda auferida em território nacional e fora de seus limites (OLIVEIRA et al., 2005, p. 407 - 408).

O tributo, assim definido no art. $3^{\circ}$ da Lei $\mathrm{n}^{\circ}$ 5.172/66 - Código Tributário Nacional (CTN), “é toda prestação pecuniária compulsória, em moeda ou cujo valor nela se possa exprimir, que não constitua sanção de ato ilícito, instituída em lei e cobrada mediante atividade administrativa plenamente vinculada." Trata-se, portanto, de uma obrigação imposta pelo Estado às pessoas físicas ou jurídicas, mesmo que não corresponda a uma atividade específica deste em relação ao sujeito passivo da obrigação principal, qual seja, contribuinte, responsável ou substituto tributário.

Para que qualquer tributo possa ser arrecadado é necessário que haja legislação vigente e na qual se estabeleçam os elementos jurídicos de sua validade. Essencialmente, tais elementos são o fato gerador da obrigação principal, o sujeito ativo e passivo, a base de cálculo, a alíquota incidente ou o valor fixo (OLIVEIRA et al., 2005, p. 28 - 30).

Para entendimento dos efeitos do controle fiscal dos preços de transferência e, até mesmo, da sua aplicação faz-se necessário conhecer alguns aspectos relacionados à tributação sobre o lucro das empresas.

O fato gerador do imposto de renda, de acordo com o CTN, art. 43, incisos I e II, é a obtenção de renda e proventos de qualquer natureza, assim entendidos como o efetivo acréscimo patrimonial em determinado lapso de tempo. Especificamente, para as pessoas jurídicas o efetivo acréscimo patrimonial pode ser verificado quando do levantamento do Balanço Patrimonial, da Demonstração do Resultado do Exercício e da Demonstração das Mutações do Patrimônio Líquido. Para exemplificar, as alterações patrimoniais tem origem na obtenção ou não de lucro líquido no exercício, no recebimento de doações ou subvenções para investimentos, na integralização de capital e no prêmio recebido na emissão de debêntures.

Posteriormente, com a promulgação da Lei Complementar $n^{\circ} 104 / 01$, foi acrescentado ao art. 43 do CTN, os seguintes parágrafos:

$\S 1^{\circ}$ A incidência do imposto independe da denominação da receita ou do rendimento, localização, condição jurídica ou nacionalidade da fonte, da origem e da forma de percepção. 
$\S 2^{\circ} \mathrm{Na}$ hipótese de receita ou de rendimento oriundos do exterior, a lei estabelecerá as condições e o momento em que se dará sua disponibilidade, para fins de incidência do imposto referido neste artigo (BRASIL, 1966).

Este acréscimo ao texto legal confere ao legislador maior liberdade de aplicação do princípio da universalidade na tributação da renda, bem como relevância a aplicação da legislação dos preços de transferência.

Além do fato gerador, a base de cálculo é um elemento imprescindível para o estabelecimento de tributos. Ela decorre das origens da obrigação tributária e determina a prestação pecuniária que será entregue pelo sujeito passivo ao Estado.

Conforme o art. 44 do CTN a base de cálculo do imposto de renda "é o montante real, presumido ou arbitrado da renda ou proventos tributáveis", cada qual com critérios próprios de aplicação definidos em lei.

A tributação com base no lucro arbitrado não decorre de uma opção exercida pelo contribuinte, ao contrário, é resultado, por exemplo, de escrituração irregular ou imprestável, da recusa de apresentação dos livros fiscais e comerciais as autoridades tributárias ou quando identificada a indevida opção de tributação. Se a opção do contribuinte for o lucro presumido, a base de cálculo é obtida a partir da aplicação de um percentual sobre a receita bruta, o qual varia de acordo com a atividade fim da empresa. Como o ajuste decorrente do preço de transferência faz sentido apenas ao contribuinte optante pela tributação do lucro real, não será abordado nesse estudo o lucro presumido.

Conceitualmente, o lucro real provém do lucro líquido apurado na escrituração comercial, denominado lucro contábil, ajustado pelas adições, exclusões e compensações expressamente previstas pela legislação do Imposto de Renda. Os ajustes podem ser positivos ou negativos, ou seja, aumentam ou diminuem o lucro de referência. Em decorrência disso, o lucro contábil pode ser diferente do lucro real. No entanto, interessa ao estudo dos preços de transferência na importação os ajustes positivos, no caso a adição de custos e despesas registrados na Demonstração do Resultado do Exercício, porém considerados não dedutíveis pela legislação pertinente quando constatado que o preço parâmetro é menor que o preço efetivamente praticado.

As pessoas jurídicas tributadas com base no lucro real, desde a vigência da Lei $n^{\circ}$ 9.430/96, art. $1^{\circ}$, podem optar pelo regime de apuração trimestral ou anual. A opção pela tributação trimestral não interfere na declaração do preço de transferência, uma vez que, as operações de comércio exterior que implicam no controle fiscal dos mesmos deverão ser comunicadas a Secretaria da Receita Federal na Declaração de Informações Econômico-Fiscais da Pessoa Jurídica (DIPJ) somente após o encerramento do exercício social.

Em ambos os regimes de apuração a alíquota aplicada sobre a totalidade da base de cálculo é de $15 \%$ (quinze por cento) mais uma alíquota adicional de $10 \%$ (dez por cento) sobre a parcela da 
base de cálculo que exceder o limite de $\mathrm{R} \$ 240.000,00$ anual ou proporcionalmente ao período de apuração. Também é permitido ao contribuinte compensar o prejuízo fiscal em até 30\% (trinta por cento) do lucro líquido ajustado nos exercícios subseqüentes, por prazo indeterminado. Para a CSLL a alíquota é de 9\% (nove por cento) aplicada sobre a base de cálculo da mesma, a qual é obtida de maneira similar a base de cálculo do IRPJ.

Uma vez definido no início do ano calendário o regime de apuração não poderá ser alterado no decorrer do período. Tal situação aplica-se tanto ao IRPJ quanto a CSLL, pois a apuração da base de cálculo desta contribuição também depende da obtenção de lucro fiscal e o valor da mesma não poderá ser deduzido para determinação do imposto de renda.

\section{Metodologia da pesquisa}

Segundo Beuren (2002) as pesquisas podem ser classificadas segundo seus objetivos, procedimentos técnicos adotados e a forma de abordar o problema.

Para a consecução do objetivo proposto esta pesquisa caracteriza-se por ser descritiva. A pesquisa descritiva permite apresentar as características de determinada população ou fenômeno, bem como identificar a relação entre variáveis (BEUREN, 2002. p. 42).

Adota-se como procedimento o estudo bibliográfico e o estudo de caso. O primeiro compreende, neste trabalho, a leitura e interpretação da legislação e publicações que fornecem subsídios para explicar e discutir conceitos e circunstâncias relacionadas à determinação do preço de transferência. O segundo consiste na obtenção dos dados necessários ao cálculo do preço parâmetro com base no Preço de Revenda menos o Lucro (PRL 60\%).

O estudo de caso foi desenvolvido em uma empresa que atua no segmento de eletroeletrônicos. As importações realizadas pela empresa não estão sujeitas ao controle fiscal do preço de transferência e compreendem componentes para serem aplicados no processo produtivo e bens para revenda sem agregação de valor. Contudo, considera-se o fato de que a empresa tem interesse em associar-se a um de seus fornecedores do exterior para a execução de empreendimento de modernização tecnológica. Essa parceria implica, entre outros, no fornecimento exclusivo de determinados componentes para serem utilizados na cadeia produtiva.

Trata-se, portanto, de estudo preliminar das implicações tributárias com base em preços de transferência decorrentes dessa associação e, por isso, a amostra utilizada na simulação limita-se a um único componente aplicado no processo produtivo. Esse componente foi escolhido por ter os valores mais representativos no volume total de importações e das vendas realizadas no exercício social de 2009. Acrescenta-se, ainda, que o mesmo atende a expectativa de lucratividade da empresa após a associação.

Por solicitação da empresa foi preservada sua identidade e as características do componente 
importado e do produto final, bem como não foi discriminado o que compõe o valor agregado. Para manter a confidencialidade das informações a empresa optou por modificá-las a partir de um fator de variação de forma que fossem mantidas as mesmas proporções.

Com relação à abordagem do problema, esta pesquisa caracteriza-se por ser qualitativa na medida em que a coleta e a interpretação dos dados não implicam na utilização de um instrumental estatístico.

\section{Apresentação e análise dos resultados}

Na simulação realizada para o cálculo do preço parâmetro é aplicada apenas a metodologia de cálculo PRL 60\%, uma vez que não seria possível, nesta fase, ter acesso as informações externas necessárias a utilização das demais metodologias.

Ressalta-se que a empresa indicou o custo médio ponderado de importação, o preço médio ponderado de venda e de venda líquido e o custo médio ponderado de produção final. No preparo dessas informações foi necessário envolver profissionais de várias áreas da empresa, como contabilidade e controladoria, custos, importação, financeira, tecnologia da informação e suporte. Estes foram orientados a proceder em conformidade com a IN - SRF n 243/02.

O custo de importação utilizado na simulação compreende o valor da mercadoria importada mais frete, seguro e o imposto de importação. Os demais tributos incidentes na importação (IPI, ICMS, PIS e COFINS) não integram o custo da mercadoria importada, uma vez que a empresa em questão enquadra-se no regime de não cumulatividade. Assim, esses tributos serão recuperados quando da venda do produto final.

Para obter o preço de venda líquido foram deduzidos do preço de venda os tributos incidentes sobre o mesmo (IPI, ICMS, PIS e COFINS), bem como os descontos incondicionais, comissões, frete e o valor dos juros nas vendas a prazo. Como a empresa possui uma política de juros consistente e as vendas do produto final em questão são realizadas apenas no mercado interno, não foi necessário ajustar os juros com base na taxa referencial SELIC, para títulos federais, proporcional ao intervalo de pagamento concedido. Por fim, o custo de produção final compreende o custo de importação mais o valor agregado no País.

O valor médio ponderado das importações, das vendas líquidas e dos custos é fundamental para proceder ao cálculo do preço parâmetro por meio do PRL 60\%. Segundo a IN - SRF n 243/02, o preço parâmetro é obtido subtraindo-se o valor da margem de lucro do valor de participação do insumo no preço de venda líquido.

A aplicação da metodologia PRL 60\% para o cálculo do preço parâmetro é demonstrado na sequência, conforme Tabela 1 . 
Tabela 1 - Aplicação do método PRL 60\% conforme IN - SRF 243/02

\begin{tabular}{clrr}
\hline Variável & \multicolumn{1}{c}{ Descrição } & \multicolumn{1}{c}{ Cálculo } & \multicolumn{1}{c}{ Resultados } \\
\hline CI & Preço médio ponderado de importação do insumo & - & $30.078,30$ \\
PV & Preço médio ponderado de venda & - & $120.376,07$ \\
PLV & Preço médio ponderado de venda líquido & - & $87.320,90$ \\
CPF & Custo médio ponderado de produção final & - & $56.935,84$ \\
A & \% do insumo no custo de produção final & $\mathrm{A}=(\mathrm{CI} / \mathrm{CPF}) * 100$ & $52,83 \%$ \\
VA & \% valor agregado & $\mathrm{VA}=(1-(\mathrm{CI} / \mathrm{CPF}))^{*} 100$ & $47,17 \%$ \\
VP & Participação do insumo no preço de venda líquido & $\mathrm{VP}=\mathrm{PLV} * \mathrm{~A}$ & $46.130,25$ \\
ML & Margem de lucro de 60\% & $\mathrm{ML}=\mathrm{VP} * 60 \%$ & $27.678,15$ \\
PP & Preço parâmetro & $\mathrm{PP}=\mathrm{VP}-\mathrm{ML}$ & $18.452,10$ \\
AJ & Valor do ajuste & $\mathrm{AJ}=\mathrm{CI}-\mathrm{PP}$ & $11.626,20$ \\
MD & Margem de divergência & $\mathrm{MB}=\mathrm{CI} / \mathrm{PP}$ & 1,63 \\
B & Unidades importadas & - & 153 \\
C & Ajuste total & $\mathrm{C}=\mathrm{AJ} * \mathrm{~B}$ & $1.778 .808,79$ \\
\hline
\end{tabular}

Fonte: Autoria própria (2009)

O valor da margem de lucro representa $60 \%$ do valor da participação do insumo no preço de venda líquido, percentual este, fixado pela legislação. Por sua vez, o valor da participação do insumo no preço de venda líquido é determinado pela aplicação do percentual de participação do insumo no custo de produção final, nesse caso 52,83\%, sobre o preço médio ponderado de venda líquido. Portanto, o preço parâmetro é na verdade a representação de $40 \%$ da participação do insumo no preço de venda líquido.

Nota-se pela metodologia de cálculo aplicada na Tabela 1 que o preço parâmetro obtido foi inferior ao custo médio ponderado de importação. A diferença entre o preço praticado e o preço parâmetro é denominada ajuste e deve ser adicionada a base de cálculo para a apuração do IRPJ e da CSLL. Neste caso específico, o ajuste compreende $\mathrm{R} \$ 11.626,20$ por unidade, totalizando $\mathrm{R} \$$ 1.778.808,79 de custos indedutíveis (Tabela 1). Sobre esse valor incide a alíquota de $15 \%$ (quinze por cento) do IRPJ mais o adicional de $10 \%$ (dez por cento) e 9\% (nove por cento) da CSLL. Portanto, em decorrência da adequação ao controle fiscal dos preços de transferência, o impacto tributário percebido pela empresa será de $\mathrm{R} \$ 580.784,88$ a mais no exercício social de 2009.

Para eliminar esse impacto tributário a margem de divergência teria que ser menor ou igual a 1,05. Portanto, como tal margem está em 1,63 (Tabela 1) permanece o ajuste. Uma das alternativas para aproximar-se da margem de divergência satisfatória, caso o preço de importação não possa ser reduzido, é rever os custos de produção, de forma a reduzir o valor agregado ao produto final.

A empresa também pode pleitear a redução do percentual da margem de lucro de $60 \%$ junto ao Ministro da Fazenda se constatada a inviabilidade do negócio decorrente desse ajuste. Para tanto, deverá indicar o prazo para vigência da margem sugerida e apresentar o demonstrativo dos custos de produção, do total anual das compras e vendas do objeto da solicitação, dos fretes e seguros e, inclusive, anexar cópia dos documentos originais que justifiquem a nova margem. 
Importa ainda, que o ajuste obtido no cálculo apresentado na Tabela 1 decorre de operações de compra que não foram realizadas com pessoas vinculadas. Portanto, infere-se que o método aplicado neste estudo não atende ao objetivo da legislação brasileira sobre preços de transferência, uma vez que os preços médios utilizados representam as condições de livre negociação. Por outro lado, não é possível generalizar essa constatação, uma vez que a simulação limitou-se a verificar a adequação da metodologia PRL 60\% para um caso específico. Acrescenta-se também que, caso o componente importado possa ser utilizado em mais de um produto final, o preço parâmetro pode divergir em razão do mesmo ser apurado com base nos preços finais de venda de cada um dos produtos industrializados.

O processo de organização dos dados utilizados no cálculo apresentado na Tabela 1 foi relatado pelas pessoas envolvidas como bastante trabalhoso, principalmente porque, não havia base de dados preparada para esse fim. Contudo, isto possibilitou constatar que a controladoria pode coordenar o fluxo de atividades inerentes ao controle dos preços de transferência, bem como indicar os responsáveis por executá-las.

Preliminarmente, parece conveniente que esse fluxo de trabalho seja realizado ao final de cada mês e corresponda: a) identificar as operações de importação que implicam controle fiscal de preços de transferência; b) separar a documentação por produto importado conforme a destinação final do mesmo; c) identificar em quais produtos finais ocorreu o emprego do insumo importado; d) reunir a documentação necessária para respaldar o cálculo (notas fiscais de venda, planilhas de custo e de controle de estoque, documentos de importação e desembaraço aduaneiro); e) verificar as limitações e escolher o método de cálculo; e) proceder ao cálculo do preço médio ponderado e do preço parâmetro e posteriormente, f) documentar em relatório.

Além disso, para que a empresa esteja apta a utilizar o preço de transferência, o mesmo deve ser inserido na perspectiva de gestão tributária e, por isso, contemplar todo o processo de negociação de preços com a empresa associada. Isto implica na atuação da controladoria em garantir a periodicidade de revisão dos preços de forma a considerar os principais pontos de aumento e redução dos mesmos, como por exemplo, flutuação cambial, vantagens e desvantagens na forma de interpretar o aparato legal, no impacto da regionalização dos negócios, bem como consolidação de uma cultura de preços de transferência na organização.

O cuidado no preparo da documentação suporte para os cálculos também deve ser singular. Adverte-se que se a empresa não estiver preparada para a fiscalização a mesma pode torna-se mais morosa, além de facilitar a exposição a outros riscos de autuação em áreas conexas como em relação aos critérios de avaliação de custos, tributação sobre a renda, alíquota de importação e valoração aduaneira e impostos indiretos. A apresentação de declaração de preço de transferência falsa implica, inclusive, na suspensão do registro do contador no Conselho Federal de 
Contabilidade.

Acrescenta-se, ainda, que para um efetivo planejamento tributário deve-se considerar o método mais adequado a situação dos negócios da empresa e, isto inclui todos os gastos envolvidos nos procedimentos adotados na elaboração da documentação e na política interna de controles.

\section{Considerações finais e recomendações}

Buscou-se neste estudo de caso identificar os reflexos tributários decorrentes da utilização do método de cálculo denominado Preço de Revenda menos o Lucro (PRL 60\%).

Embora a legislação brasileira sobre preços de transferência permita ao contribuinte escolher o método que lhe traga o menor ajuste, na prática existem fatores limitantes como, por exemplo, a utilização consistente de um dos métodos para todas as operações realizadas durante o exercício social. Isso inviabiliza a utilização do método PIC, caso não haja produtos similares ou quando o fornecimento do produto é exclusivo. Além disso, é exigida do contribuinte uma extensa documentação e dispendiosa validação da mesma, principalmente para a utilização do método CPL.

Os resultados apurados na Tabela 1 reforçam a tese que o método de cálculo do preço parâmetro PLR 60\% pode distorcer a real motivação da legislação sobre preços de transferência e sujeitar as empresas aos ajustes fiscais, mesmo quando não manipulam os preços. Os cálculos simulados indicam que em decorrência da adequação ao controle fiscal dos preços de transferência o impacto tributário percebido pela empresa neste estudo de caso seria de $\mathrm{R} \$ 580.784,88$ a mais.

Acrescenta-se que as operações de compra do insumo e de venda do produto final que serviram à simulação apresentada não estavam sujeitas ao controle fiscal do preço de transferência. Contudo, a utilização da metodologia PRL 60\% evidencia que mesmo nessas condições ocasionou aumento da base de cálculo do IRPJ e da CSLL.

Por outro lado, não é possível generalizar essa constatação, uma vez que, esta simulação limita-se a verificar a adequação da metodologia PRL 60\% para um caso específico. Além disso, não foi possível medir nesta pesquisa os gastos necessários a operacionalização dos controles internos dos preços de transferência e, nem as demais vantagens da parceria que será estabelecida entre a empresa estudada e a outra no exterior, dentre elas, a possibilidade de alavancar as exportações com a utilização do regime aduaneiro drawback.

Acrescenta-se que a complexidade técnica e burocrática associada aos preços de transferência reflete a importância e significância do planejamento tributário dentro de cada organização. Sob essa perspectiva, o planejamento tributário quando aliado ao planejamento estratégico indicará o método de cálculo do preço parâmetro que atenda às características dos negócios da empresa. Para tanto, as oportunidades estão em considerar na reestruturação dos negócios medidas de redução dos custos de produção e investimentos em tecnologia da informação. 
Para minimizar os riscos de autuação fiscal é necessário definir claramente os parâmetros de comprovação dos preços praticados entre empresas vinculadas. As autuações fiscais poderão ser danosas se os procedimentos de formulação e guarda da documentação não forem condizentes e adequados. Ainda, as atribuições e responsabilidades de cada setor devem ser claras e elaboradas de forma a prever um controle ao menos mensal das operações e a economia de recursos. É nesse aspecto que a área de controladoria pode assumir função estratégica na reestruturação dos negócios.

Os resultados reforçam recomendações sobre novas pesquisas em relação a avaliar o impacto tributário na determinação do preço de transferência. Dentre as sugestões apresentam-se: a) uma análise que verifique o comportamento dos ajustes fiscais dos preços de transferência nas operações de drawback; b) pesquisas que avaliem se as empresas vinculadas adotam diferentes práticas de preços de transferência no comércio interno e externo.

\begin{abstract}
The international business companies tend to direct intra-firm profits more conveniently using, among other mechanisms, the transfer pricing policy. The tax consequences resulting from such operations led several countries, including Brazil, to fear the loss of tax revenues. The Brazilian legislation on transfer pricing by means of specific methodology determines the maximum deductible calculation of costs in importing and recognition of minimum income in exports of goods, rights and services. The aim of this study is to identify the tax consequences arising from the use of calculation method called the Resale Price Less Profit (60\% PRL). This descriptive study is divided into two phases: literature review and case study conducted in a consumer electronics company. The results obtained allow inferring that the calculation of the price parameter, if limited to $60 \%$ PRL methodology, can significantly influence the bottom line and contribute to the number of arbitration would be the right price. Consequently, its use causes an increase in basis of calculation of taxes on income.
\end{abstract}

Key-words: transfer pricing; importation; tax planning.

\title{
Referências
}

BEUREN, I. M. (org). Como elaborar trabalhos monográficos em contabilidade: teoria e prática. 2. ed. São Paulo: Atlas, 2002.

BORGES, A. S. O método do preço de revenda menos o lucro - PRL na legislação brasileira. In: BORGES, A. S.; FERNANDES, E. C.; PEIXOTO, M. M. (Coord.). Manual de preços de transferência no Brasil. São Paulo: MP Ed., 2007.

BRASIL. Lei no 5.172, de 25 de outubro de 1966. Disponível em:

<http://www.planalto.gov.br/ccivil_03/Leis/L5172.htm>. Acesso em: 05 jun. 2010.

. Lei no 6.404, de 15 de dezembro de 1976. Disponível em:

<http://www.planalto.gov.br/ccivil_03/Leis/L6404consol.htm>. Acesso em: 05 jun. 2010.

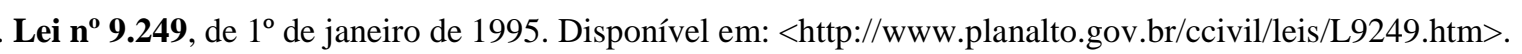
Acesso em: 05 jun. 2010.

Lei no 9.430, de 27 de dezembro de 1996. Disponível em:

<http://www.planalto.gov.br/ccivil_03/Leis/L9430.htm>. Acesso em: 05 jun. 2010. 
Decreto no 2.498, de 13 de fevereiro de 1998. Disponível em:

<http://www.planalto.gov.br/ccivil_03/decreto/D2498.htm>. Acesso em: 05 jun. 2010.

Lei $\mathbf{n}^{\mathbf{0}}$ 9.959, de 27 de janeiro de 2000. Disponível em:

<http://www.planalto.gov.br/ccivil_03/Leis/L9959.htm >. Acesso em: 05 jun. 2010.

. Lei Complementar $\mathbf{n}^{\mathbf{0}} \mathbf{1 0 4}$, de 10 de janeiro de 2001. Disponível em:

<http://www.planalto.gov.br/ccivil_03/Leis/LCP/Lcp104.htm>. Acesso em: 05 jun. 2010.

. Lei no 11.281, de 20 de fevereiro de 2006. Disponível em: <http://www.planalto.gov.br/ccivil_03/_Ato20042006/2006/Lei/L11281.htm>. Acesso em: 05 jun. 2010.

Medida Provisória no 478, de 29 de dezembro de 2009. Disponível em:

<http://www.planalto.gov.br/ccivil/_Ato2007-2010/2009/Mpv/478.htm>. Acesso em: 20 jun. 2010.

. SECRETARIA DA RECEITA FEDERAL. Instrução normativa no 32, de 30 de março de 2001. Disponível em: <http://www.receita.fazenda.gov.br/Legislacao/ins/2001/in0322001.htm>. Acesso em: 05 jun. 2010.

. SECRETARIA DA RECEITA FEDERAL. Instrução normativa no 243, de 11 de novembro de 2002. Disponível em: <http://www.receita.fazenda.gov.br/legislacao/Ins/2002/in2432002.htm>. Acesso em: 05 jun. 2010.

ERNEST; YOUNG. 2010 Global transfer pricing: addressing the challenges of globalization. Disponível em: <http://www.ey.com/GL/en/Services/Tax/International-Tax/2010-Global-Tranfer-Pricing-Survey>. Acesso em: 20 dez. 2011.

ESNOLDE, A. L. et al. Percepção dos controllers em relação à gestão tributária. In: CONGRESSO USP DE CONTROLADORIA E CONTABILIDADE, 9, 2009, São Paulo. Anais... São Paulo: USP, 2009.

FERNANDES, E. C. Conceitos básicos referentes ao controle fiscal dos preços de transferência. In: BORGES, A. S.; FERNANDES, E. C.; PEIXOTO, M. M. (Coord). Manual de preços de transferência no Brasil. São Paulo: MP Ed., 2007.

FRANÇOSO, T. F. Operações controladas segundo a legislação brasileira de preços de transferência. In: BORGES, A. S.; FERNANDES, E. C.; PEIXOTO, M. M. (Coord). Manual de preços de transferência no Brasil. São Paulo: MP Ed., 2007.

HANSEN, D. R.; MOWEN, M. M. Descentralização: contabilidade por responsabilidade, avaliação de desempenho e preços de transferência. In: Gestão de Custos. São Paulo: Pioneira Thomson Learning, 2003.

HORNGREN, Charles T.; SUNDEM, Gary L.; STRATTON, William O. Contabilidade gerencial. São Paulo: Prentice Hall, 2004.

LIMA NETO, João Fernandes de. O controle dos preços de transferência como instrumento de prevenção aos crimes contra a ordem econômica. 212 f. Dissertação (Mestrado em Direito Econômico), Universidade Federal da Paraíba. João Pessoa, 2007.

NASCIMENTO, A. M.; REGINATO, L. (Org.). Controladoria: um enfoque na eficácia organizacional. São Paulo: Atlas, 2007.

OLIVEIRA, L. M. de et al. Manual de contabilidade tributária. 6 ed. São Paulo: Atlas, 2007.

PRICEWATERHOUSECOOPERS. Preço de transferência: transfer pricing. 2 ed. São Paulo: Atlas, 2000.

SAGAZ, F. R. A contribuição da controladoria na coordenação da gestão tributária em operações de compras. 143 f. Dissertação (Mestrado em Contabilidade), Universidade Federal de Santa Catarina. Florianópolis, 2009.

SAGAZ, F. R.; SAGAZ, C. A. A participação da controladoria na gestão estratégica da tributação reduzindo os custos das importações. In: CONGRESSO BRASILEIRO DE CUSTOS, 14, 2007, João Pessoa. Anais... João Pessoa: CBC, 2007.

SECRETARIA DA RECEITA FEDERAL. Preços de transferência. 2005. Disponível em:

<http://www.receita.fazenda.gov.br/pessoajuridica/dipj/2005/pergresp2005/pr672a733.htm>. Acesso em: 05 abr. 2010. 
SILVA, L. L. Contabilidade avançada e tributária. 2 ed. São Paulo: IOB, 2007.

\section{Dados dos autores:}

\section{Nome: Silvia Consoni}

Filiação institucional: Universidade Federal de Santa Catarina

Departamento: Ciências Contábeis

Função ou cargo ocupado: Bacharel em Ciências Contábeis

Endereço para correspondência: R. Alto Piriqui, 304. Bairro Braga. São José dos Pinhais - PR. CEP.: 83020-170

Telefone para contato: (41) 9610-3855

e-mail: silviaconsoni@yahoo.com.br

\section{Nome: Sérgio Murilo Petri}

Filiação institucional: Universidade Federal de Santa Catarina

Departamento: Ciências Contábeis

Função ou cargo ocupado: Professor Adjunto

Endereço para correspondência: Rua João Meirelles, 1179. Apto 33, Bl 5. Bairro Abraão.

Florianópolis - SC. CEP.: 88085-201

Telefone para contato: (48) 3721-9383

e-mail:smpetri@gmail.com

\section{Nome: Alexandre Zoldan da Veiga}

Filiação institucional: Universidade Federal de Santa Catarina

Departamento: Ciências Contábeis

Função ou cargo ocupado: Professor

Endereço para correspondência: Campus Universitário. Bairro Trindade. Florianópolis -SC. CEP.: 88040-900

Telefone para contato: (48) 3721-9383

e-mail: azveiga@floripa.com.br

Enviado em: 02/03/2011

Aprovado em: 15/12/2011 